\title{
Copy Number Variation of Multiple Genes in SAPHO Syndrome
}

\author{
Changlong Guo $\mathbb{D}^{\mathbb{D}}$, Xin Tian, Feifei Han, Lihong Liu, Jianen Gao $\mathbb{D}^{\mathbb{D}}$, and Xu Ma
}

\begin{abstract}
Objective. SAPHO (synovitis, acne, pustulosis, hyperostosis, osteitis) syndrome is a type of rare chronic aseptic inflammation of unknown etiology. To date, no research to our knowledge has reported copy number variation $(\mathrm{CNV})$ of genes that could affect predisposition to SAPHO syndrome. We investigated the association between CNV profile and SAPHO syndrome.

Methods. We used array comparative genomic hybridization (CGH) to screen for CNV in a nuclear family including 2 patients and a healthy control. We then validated the copy numbers of candidate genes found in the array CGH assay and other candidate genes by TaqMan real-time PCR in 360 case and control samples.

Results. Ten regions from 8 chromosomes were found to have abnormal gene copies in the nuclear family, so the CNV of candidate genes (ADAM5, CSF2RA, IL3RA, and 9 other genes) were tested by TaqMan PCR. Significant copy number loss of CSF $2 R A(\mathrm{p}=0.000)$ and NOD2 $(\mathrm{p}=0.005)$, and significant copy number gain of MEGF6 ( $\mathrm{p}=0.002)$ and ADAM5 $(\mathrm{p}=0.000)$ were seen in patients with SAPHO compared with controls at the $\mathrm{a}=0.05$ level. There were no differences in the other 8 candidate genes between patient and control samples $(\mathrm{p}>0.05)$.

Conclusion. Our study established the first association between CNV in CSF2RA, NOD2, MEGF6, and $A D A M 5$ and SAPHO syndrome. These findings may offer insight into the pathogenesis of SAPHO and provide the basis for improved diagnosis and treatment. (First Release April 152020 ; J Rheumatol 2020;47:1323-9; doi:10.3899/jrheum.181393)
\end{abstract}

Key Indexing Terms:

SAPHO SYNDROME

ARRAY COMPARATIVE GENOMIC HYBRIDIZATION

\section{COPY NUMBER VARIATION TAQMAN PCR}

\begin{abstract}
SAPHO (synovitis, acne, pustulosis, hyperostosis, osteitis) syndrome, a rare disease with an estimated prevalence of less than 1 in $10,000^{1}$, was first identified in $1987^{2}$. SAPHO syndrome can occur at any age ${ }^{3}$, and its exact etiology is unknown. However, a large body of literature supports a pathogenesis involving a combination of genetic, infectious, and immunological components ${ }^{4}$. Experiments in mice indicate that SAPHO is associated with mutations in PSTPIP1,
\end{abstract}

From the National Research Institute for Family Planning, Beijing; The No. 1 Hospital of Shijiazhuang, Shijiazhuang; Shijiazhuang Maternity Hospital, Shijiazhuang; and Beijing Chao-Yang Hospital, Capital Medical University, Beijing, China.

Supported by grants 0102012 DFB30130 from the International Science

\& Technology Cooperation Program of China; 2016YFC1000300,

20161000307, 2016YFC1000803, and 2017YFC1002000 from the

National Key Research and Development Program; and 81501418 from

the National Natural Science Fund.

C. Guo, MD, PhD, National Research Institute for Family Planning;

$X$. Tian, BS, The No. 1 Hospital of Shijiazhuang, Shijiazhuang Maternity

Hospital; F. Han, MD, PhD, Beijing Chao-Yang Hospital, Capital

Medical University; L. Liu, MD, PhD, Beijing Chao-Yang Hospital,

Capital Medical University; J. Gao, MD, PhD, National Research

Institute for Family Planning; X. Ma, MD, PhD, National Research

Institute for Family Planning. Dr. Guo and Xin Tian contributed equally

to this report.

Address correspondence to Prof. J. Gao, Center for Genetics, National

Research Institute for Family Planning, 12 Dahuisi Road, Haidian,

Beijing, 100081,China.E-mail: gaojianen@nrifp.org.cn

Accepted for publication September 27, 2019.
PSTPIP $^{5}$, and NOD2 genes $^{6,7}$, but the genetic basis of human SAPHO syndrome remains poorly understood.

Copy number variation $(\mathrm{CNV})$ is widespread in human populations, with $5 \%-10 \%$ of the human reference genome showing CNV in healthy individuals ${ }^{8,9}$. Several studies have concluded that variation in DNA copy number may influence the expression of genes or even alter their structure, thus contributing to substantial phenotypic variation. Moreover, $\mathrm{CNV}$ of genes causes a variety of human genetic diseases ${ }^{10}$.

Little is known about $\mathrm{CNV}$ as a potential risk factor for SAPHO syndrome; we screened the CNV profile in a nuclear family using array comparative genomic hybridization $(\mathrm{CGH})$. We then further confirmed the candidate $\mathrm{CNV}$ genes in a larger sample size (156 SAPHO cases and 204 healthy controls) using TaqMan real-time PCR. We hope to propose the potential application of CNV evaluation in individuals at high risk of developing SAPHO syndrome, and the use of CNV genes as candidates for gene therapy.

\section{MATERIALS AND METHODS}

In the first stage, a core family with SAPHO syndrome was identified [mother: age 51 yrs, with SAPHO syndrome, with palmoplantar pustolosis and osteoarticular symptoms (anterior chest wall, spine, peripheral skeleton), duration of disease 8 yrs; daughter: age 22 yrs, with SAPHO syndrome, with osteoarticular symptoms (anterior chest wall, spine), duration of disease $1.5 \mathrm{yrs}$; father: age $53 \mathrm{yrs}$, healthy control]. The second group comprised 156 patients with SAPHO syndrome (92 women, 64

Personal non-commercial use only. The Journal of Rheumatology Copyright @ 2020 . All rights reserved. 
men; average age $41.4 \pm 0.08$ yrs) and 204 controls (122 women, 82 men; average age $59.1 \pm 0.08$ yrs; Table 1). All individuals were enrolled from Beijing Chaoyang Hospital and were matched for ethnic and geographic characteristics. SAPHO syndrome was diagnosed according to the criteria of Kahn, et al ${ }^{11}$.

The study was approved by the Ethics Committee of the National Research Institute for Family Planning (registration no. 2201512), and all participants provided written informed consent.

DNA isolation. Participants' peripheral blood samples were collected into tubes containing EDTA. DNA extraction was carried out using the RelaxGene Blood DNA System (Tiangen Biotech) according to the manufacturer's instructions. Array CGH analysis was performed using $4 \times 180 \mathrm{~K}$ commercial arrays (Capitalbio Technology Corp.). DNA labeling, hybridization, and washing were performed according to the manufacturer's instructions. After hybridization, arrays were scanned in a dual-laser scanner, and images were extracted and analyzed using Agilent CytoGenomics software. Probes with fewer than 2 valid replicate values or probes that showed SD above 0.1 between replicate values were excluded. Chromosomal regions with a ratio between 1.11 and 1.41 were scored as "gained" and those with a ratio of 1.41 or greater were scored as "amplified." Chromosomal regions with a ratio of between 0.84 and 0.73 were scored as "loss," whereas a second threshold for loss was set for regions showing a ratio $<0.73$.

TaqMan quantitative PCR ( $q P C R)$. TaqMan qPCR was used to identify candidate genes. Primers and fluorescence-labeled probes are shown in Table 2. qPCR was performed in a final volume of $25 \mu 1$ including $20 \mathrm{ng}$ of extracted DNA and $20 \mu \mathrm{l}$ of PCR mixture. All qPCR reactions were run for 45 cycles. The $\mathrm{Ct}$ value of each gene was recorded and $2-^{\Delta \mathrm{Ct}}(\Delta \mathrm{Ct}=$ $\mathrm{Ct}$ target gene - Ct RNase P) was used to determine the CNV of each sample.

Statistical analysis. Clinical data were described as mean \pm SD. Comparison of cases and controls was by Pearson chi-square test or Fisher's exact test. Statistical analyses were performed using SPSS version 13.0 (SPSS Inc.); $\mathrm{p}<0.05$ was considered statistically significant.

\section{RESULTS}

We conducted a 2-stage candidate gene study to test the association of CNV and SAPHO syndrome. First, through array $\mathrm{CGH}$ analysis, we identified several aberrant chromosome regions shared by 2 of the core family patients with SAPHO syndrome: q11 region of chromosome 11 was deemed as

Table 1. General characteristics of patients with SAPHO syndrome $(\mathrm{n}=$ 156 ) in this study.

\begin{tabular}{lc}
\hline Characteristic & $\mathrm{N}(\%)$ \\
\hline Sex & \\
$\quad$ Female & $92(59)$ \\
$\quad$ Male & $64(41)$ \\
Skin manifestations & $7(4.5)$ \\
$\quad$ None & $102(65.4)$ \\
Palmoplantar pustolosis & $17(10.9)$ \\
Severe acne & $25(16.0)$ \\
Palmoplantar pustulosis + psoriasis vulgaris & \\
Osteoarticular symptoms & $2(1.3)$ \\
$\quad$ None & $35(22.4)$ \\
$\quad$ Anterior chest wall & $57(36.5)$ \\
Anterior chest wall + spine & $26(16.7)$ \\
$\quad$ Anterior chest wall + peripheral skeleton & $36(23.1)$ \\
$\quad$ Anterior chest wall + spine + peripheral skeleton & \\
\hline
\end{tabular}

SAPHO: synovitis, acne, pustulosis, hyperostosis, osteitis syndrome. amplification, including OR4S2, OR4C6; 5 regions (q31.3 of chromosome 1, p11.22 of chromosome $8, \mathrm{p} 12$ of chromosome 19, q11.23-q12.1 of chromosome 22, and q13.1 of chromosome 22) were deemed as gain, including ADAM5P, $A P O B E C 3 A, C F H R 3$, etc. Three regions were deemed as loss (q13 of chromosome 2, p22.3 of chromosome 9, p22.33 of chromosome X), including CSF2RA, MIR3690, IL3RA, etc. Detailed results are shown in Table 3.

In the validation stage, we chose ADAM5, CSF2RA, $I L 3 R A$, and 9 other genes associated with inflammation or autoimmune (AAGAB, HRVR, IGSF9, PSTPIP1, PSTPIP2, LPIN2, IRAK3, NOD2, MEGFO) as candidate genes. TaqMan qPCR was used to determine the variations of candidate gene copy numbers in 156 patients with SAPHO syndrome and 204 controls. Finally, 4 of 12 chosen genes were found to have significantly different copy numbers between patients with SAPHO syndrome and controls at the a $=0.05$ level, of which CSF2RA (ratio ${ }_{\mathrm{SAPHO} / \mathrm{HC}}=0.597$, $\mathrm{p}=0.000$ ) and NOD2 (ratio ${ }_{\mathrm{SAPHO} / \mathrm{HC}}=0.470, \mathrm{p}=0.002$ ) had fewer gene copies, and MEGF6 (ratio ${ }_{\mathrm{SAPHO} / \mathrm{HC}}=1.407$, $\mathrm{p}=0.001$ ) and ADAM5 (ratio SAPHO/HC $=1.713, \mathrm{p}=0.000$ ) had more copies, compared with healthy controls. There were no differences in the other 8 candidate genes between patients with SAPHO syndrome and control samples ( $p$ > 0.05; Tables 4A and 4B; Figures 1 and 2). In subsequent analysis, patients with SAPHO syndrome were subgrouped according to osteoarticular and skin symptoms (Tables 4A and 4B). The results showed the gene copies of CSF2RA, NOD2, ADAM5, and MEGF6 were significantly different in palmoplantar pustulosis; meanwhile, CSF2RA was found to be strongly correlated with osteoarticular symptoms; the results achieved statistical differences in all subgroups. As for other symptoms, perhaps because of small sample sizes, the results showed inconsistencies among different subgroups, especially in the no-skin-manifestation samples, so the results should be treated cautiously.

\section{DISCUSSION}

SAPHO syndrome is a type of rare chronic aseptic inflammation, and its complete pathogenesis is unknown. Previous investigations showed that PSTPIP1, PSTPIP2, and LPIN2 were associated with SAPHO syndrome in mice ${ }^{5,12,13}$. Other research showed that dysregulation of interleukin 1 (IL-1) signaling caused sterile osteomyelitis in PSTPIP2-deficient mice ${ }^{10,14}$. However, genetic screening found no specific variants in PSTPIP1, PSTPIP2, NOD2, or LPIN2 in patients with SAPHO syndrome ${ }^{7}$. We used array CGH and TaqMan qPCR to determine the role of genetic factors in the development of SAPHO. For the first time, we demonstrated that copy number loss of CSF2RA and NOD2, and copy number gain of MEGF6 and ADAM5, contribute to SAPHO syndrome.

CSF2RA is located on $\mathrm{Xp} 22.33$ and $\mathrm{Yp} 11.2$, and is inherited in an autosomal recessive manner ${ }^{15}$. The CSF2RA protein functions as the alpha subunit of the heterodimeric 


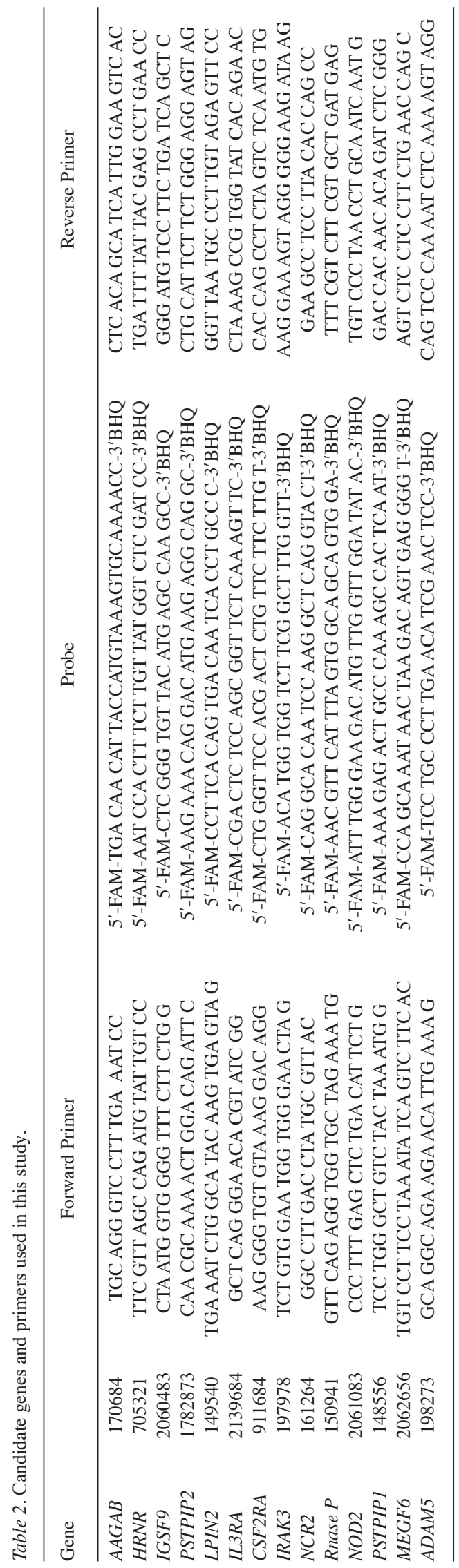

receptor for colony-stimulating factor 2 , a cytokine that controls the production, differentiation, and function of granulocytes and macrophages ${ }^{16,17}$. We demonstrated that the CSF2RA copy number was significantly decreased in patients with SAPHO syndrome, which would likely decrease its interaction with granulocyte-macrophage colony-stimulating factor (GM-CSF) and its receptor, resulting in an accumulation of GM-CSF in the peripheral blood of patients. Previous research showed GM-CSF played a pivotal role in regulating inflammatory networks, and aberrant expression of GM-CSF was found in some autoimmune diseases, including rheumatoid arthritis ${ }^{18,19}$ and synovitis $^{20,21,22}$. In synovitis, abundant GM-CSF can promote joint inflammation by secreting large amounts of tumor necrosis factor- $\alpha$ (TNF- $\alpha$ ) and IL- ${ }^{23}$. Indeed, elevated IL-6 and TNF concentrations have been observed in the serum of patients with SAPHO syndrome ${ }^{24}$, while the use of anti-TNF agents has proven a valid alternative for patients unresponsive to conventional treatments, including nonsteroidal antiinflammatory drugs, corticosteroids, disease-modifying antirheumatic drugs, and bisphosphonates ${ }^{25}$. GM-CSF also enhances IL-1 $\beta$ production by macrophages by regulating lipopolysaccharide (LPS)-mediated pro-IL-1 $\beta$ expression ${ }^{26}$. Excessive IL-1 $\beta$ can lead to osteitis, a major feature of SAPHO syndrome, and enhance mesenchymal cell differentiation in osteoblasts ${ }^{27}$. SAPHO syndrome has been shown to partly depend on genetically encoded overproduction of IL- $1 \beta^{27}$. Additionally, excessive IL- $1 \beta$ triggers an innate immune response in the $\mathrm{skin}^{28}$, including in vivo inflammatory responses to Propionibacterium acnes, another major phenotype of SAPHO syndrome, which is in accord with the acne phenotype of SAPHO syndrome. We therefore speculate that the excess GM-CSF induced by decreased CSF2RA is a major cause of SAPHO syndrome development.

NOD2 is located in chromosome 16, a region highly associated with some systemic autoinflammatory diseases. $N O D 2$ was the first susceptibility gene identified in inflammatory bowel disease ${ }^{29}$. Previous results described genetic variants of NOD2 in a series of systemic autoinflammatory diseases, including Crohn disease, Blau syndrome, and Yao syndrome ${ }^{30}$. NOD2 is also associated with skin diseases $^{31}$, and it plays a pivotal role in the immune response to intracellular bacterial LPS by recognizing the muramyl dipeptide and activating the NFKB protein $^{31}$; and delayed and ineffective recognition of a localized bacterial infection in the absence of NOD2 protein can lead to increased bacterial load and a delayed, more severe local inflammatory response ${ }^{32}$. Given its important role in autoinflammatory diseases, much effort has been made to determine its relationship with SAPHO syndrome. However, no genetic variants were found: we observed that $N O D 2$ copy number losses instead of genetic variants were involved in patients with SAPHO syndrome, and this represents significant progress in SAPHO research. 
Table 3. General information on candidate genes in the nuclear family in this study.

\begin{tabular}{|c|c|c|c|c|c|c|c|c|}
\hline Chr & Cytoband & Probes & Amp & Gain & Loss & Del & $\mathrm{p}$ & Genes \\
\hline 1 & $\mathrm{q} 31.3$ & 3 & 0 & 0.79 & 0 & 0 & $2.21 \mathrm{E}-10$ & CFHR3, CFHR1 \\
\hline 2 & q13 & 10 & 0 & 0 & -0.46 & 0 & $2.56 \mathrm{E}-13$ & MALL, NPHP1, NCRNA00116 \\
\hline 8 & $\mathrm{p} 11.22$ & 12 & 0 & 0.97 & 0 & 0 & $7.86 \mathrm{E}-51$ & $A D A M 5 P, A D A M 3 A$ \\
\hline 9 & $\mathrm{p} 22.3$ & 17 & 0 & 0 & -0.53 & 0 & $5.35 \mathrm{E}-25$ & TTC $39 B$ \\
\hline 11 & q11 & 4 & 6.54 & 0 & 0 & 0 & $4.61 \mathrm{E}-10$ & OR4S2, OR4C6 \\
\hline 19 & p12 & 5 & 0 & 0.74 & 0 & 0 & $4.53 \mathrm{E}-12$ & \\
\hline 22 & $\mathrm{q} 11.23-\mathrm{q} 12.1$ & 20 & 0 & 0.83 & 0 & 0 & $7.48 \mathrm{E}-64$ & $I G L L 3 P, L R P 5 L, C R Y B B 2 P 1$ \\
\hline 22 & $\mathrm{q} 13.1$ & 3 & 0 & 0.89 & 0 & 0 & $3.07 \mathrm{E}-12$ & АРОВЕС $3 A, A P O B E C 3 B$ \\
\hline $\mathrm{X}$ & $\mathrm{p} 22.33$ & 17 & 0 & 0 & -0.43 & 0 & $3.78 \mathrm{E}-18$ & CSF $2 R A, M I R 3690, I L 3 R A$ \\
\hline
\end{tabular}

Chr: chromosome; Amp: amplification; Del: deletion.

Table 4A. Copy number variation ratio of candidate genes in patients with SAPHO syndrome and healthy controls.

\begin{tabular}{|c|c|c|c|c|c|c|}
\hline & PSTPIP1 & $I R A K 3$ & $A A G A B$ & $A D A M 5$ & $C S F 2 R A$ & $I L 3 R A$ \\
\hline Controls, $n=204$ & $0.71 \pm 0.19$ & $1.01 \pm 0.19$ & $0.62 \pm 0.12$ & $1.96 \pm 0.67$ & $1.05 \pm 0.41$ & $0.65 \pm 0.17$ \\
\hline Cases, $\mathrm{n}=156$ & $0.66 \pm 0.30$ & $0.98 \pm 0.40$ & $0.52 \pm 0.12$ & $3.35 \pm 3.50$ & $0.62 \pm 0.17$ & $0.58 \pm 0.32$ \\
\hline $\mathrm{p}$ & 0.575 & 0.659 & 0.382 & 0.000 & 0.000 & 0.508 \\
\hline $\mathrm{ACW}$ & $0.62 \pm 0.11$ & $1.01 \pm 0.58$ & $0.50 \pm 0.10$ & $4.60 \pm 5.03 *$ & $0.59 \pm 0.12 * *$ & $0.65 \pm 0.49$ \\
\hline $\mathrm{ACW}+$ peripheral skeleton & $0.64 \pm 0.10$ & $0.93 \pm 0.19$ & $0.52 \pm 0.10$ & $3.28 \pm 3.54 *$ & $0.60 \pm 0.14 * *$ & $0.55 \pm 0.21$ \\
\hline $\mathrm{ACW}+$ spine & $0.64 \pm 0.12$ & $0.95 \pm 0.12$ & $0.51 \pm 0.13$ & $4.02 \pm 3.05 * *$ & $0.65 \pm 0.16^{* *}$ & $0.52 \pm 0.14$ \\
\hline $\mathrm{ACW}+$ spine + peripheral skeleton & $0.64 \pm 0.11$ & $0.94 \pm 0.19$ & $0.52 \pm 0.07$ & $2.62 \pm 2.60$ & $0.67 \pm 0.13 * *$ & $0.61 \pm 0.19$ \\
\hline PPP & $0.64 \pm 0.10$ & $0.98 \pm 0.35$ & $0.51 \pm 0.09$ & $3.04 \pm 2.81 * *$ & $0.63 \pm 0.14 * *$ & $0.58 \pm 0.23$ \\
\hline Psoriasis vulgaris & $0.67 \pm 0.13$ & $0.92 \pm 0.28$ & $0.54 \pm 0.13$ & $4.39 \pm 5.46$ & $0.64 \pm 0.18$ & $0.65 \pm 0.47$ \\
\hline Severe acne & $0.58 \pm 0.13$ & $0.86 \pm 0.22$ & $0.47 \pm 0.08$ & $4.69 \pm 4.55^{*}$ & $0.57 \pm 0.11 * *$ & $0.54 \pm 0.29$ \\
\hline None & $0.59 \pm 0.08$ & $0.97 \pm 0.08$ & $0.60 \pm 0.15$ & $3.08 \pm 2.99$ & $0.67 \pm 0.06$ & $0.51 \pm 0.07$ \\
\hline
\end{tabular}

$* \mathrm{p}<0.05 . * * \mathrm{p}<0.01$. SAPHO: synovitis, acne, pustulosis, hyperostosis, osteitis; ACW: anterior chest wall; PPP: palmoplantar pustulosis.

Table 4B. Copy number variation ratio of candidate genes in patients with SAPHO syndrome and healthy controls.

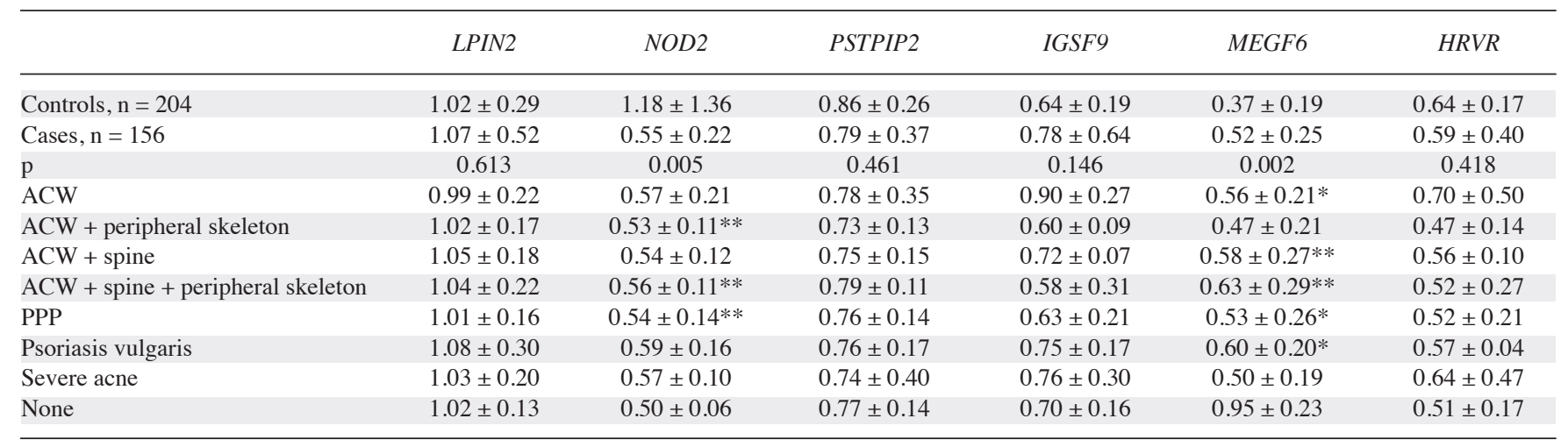

$* \mathrm{p}<0.05 . * \mathrm{p}<$ < 0.01. SAPHO: synovitis, acne, pustulosis, hyperostosis, osteitis; ACW: anterior chest wall; PPP: palmoplantar pustulosis.

We also showed that the copy numbers of MEGF6 and ADAM5 were higher in patients with SAPHO syndrome than in healthy controls. Although we inferred that these differences may increase the risk of acne and pustulosis, little is known about MEGF6 and ADAM5 proteins, so further study is required.

We established the first association between CNV in CSF2RA, NOD2, MEGF6, and ADAM5 and SAPHO syndrome. These findings may provide insight into the pathogenesis of SAPHO syndrome, and perhaps a basis for diagnosis and treatment. However, further studies are required to elucidate the pathogenesis of SAPHO syndrome.

\section{ACKNOWLEDGMENT}

We thank all participants for their contributions to the research. We thank Sarah Williams, PhD, from Liwen Bianji, Edanz Group China, for editing the English text of a draft of this report.

\section{REFERENCES}

1. Magrey M, Khan MA. New insights into synovitis, acne, pustulosis, hyperostosis, and osteitis (SAPHO) syndrome. Curr Rheumatol Rep 2009; $11: 329-33$. 
A

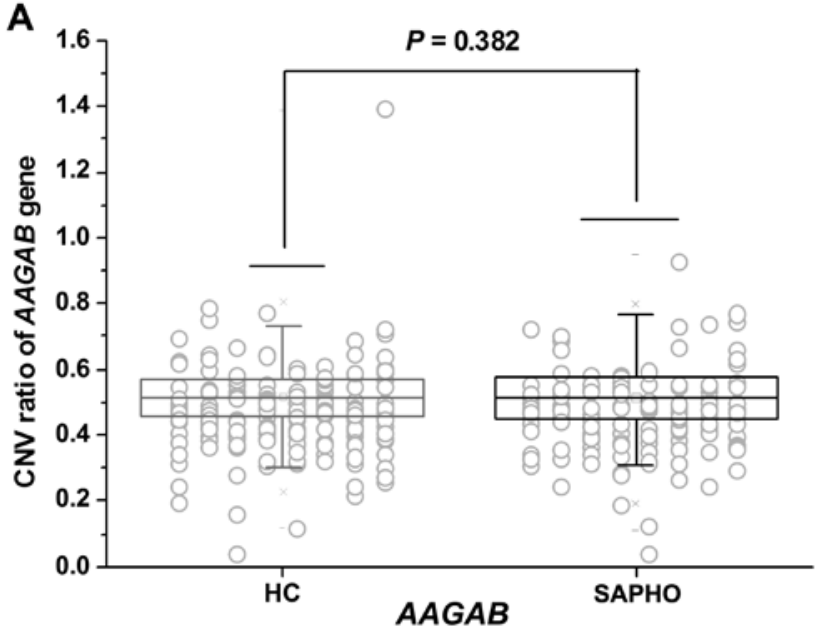

\section{C}

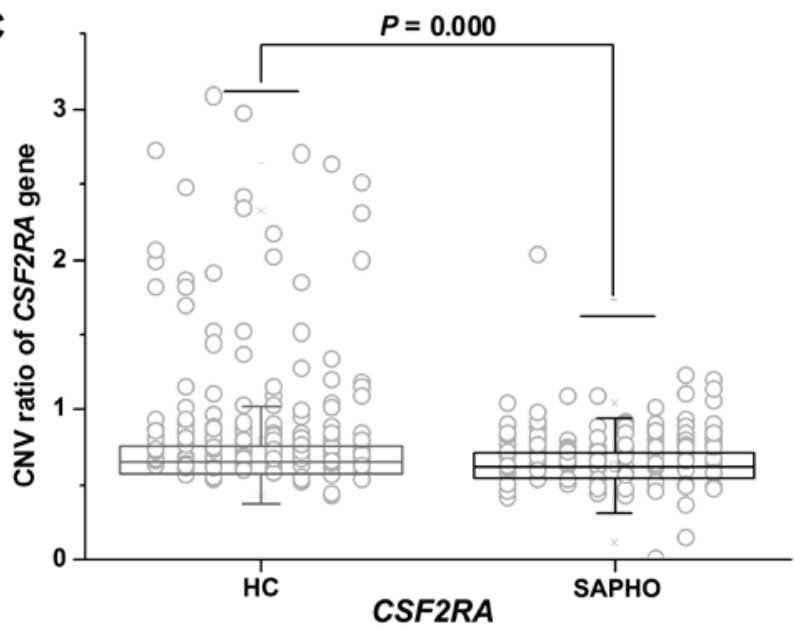

$\mathbf{E}$

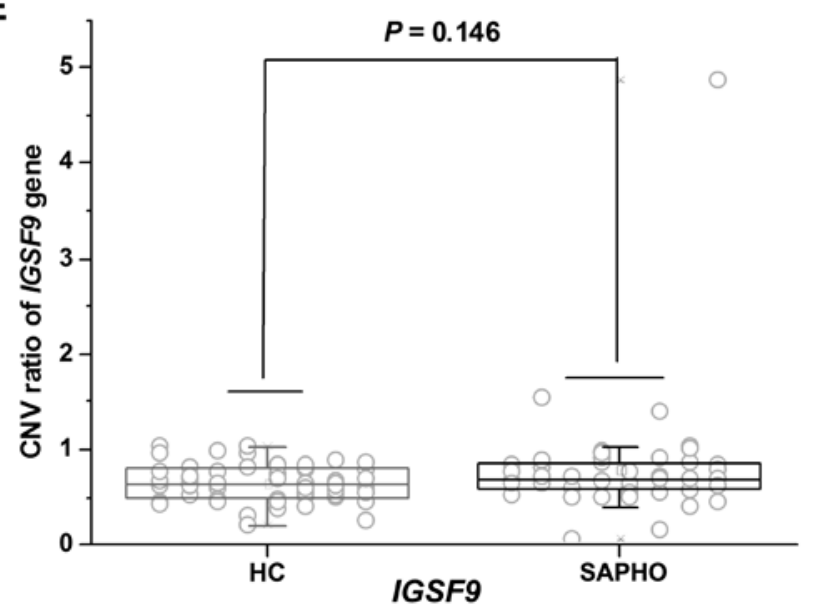

B
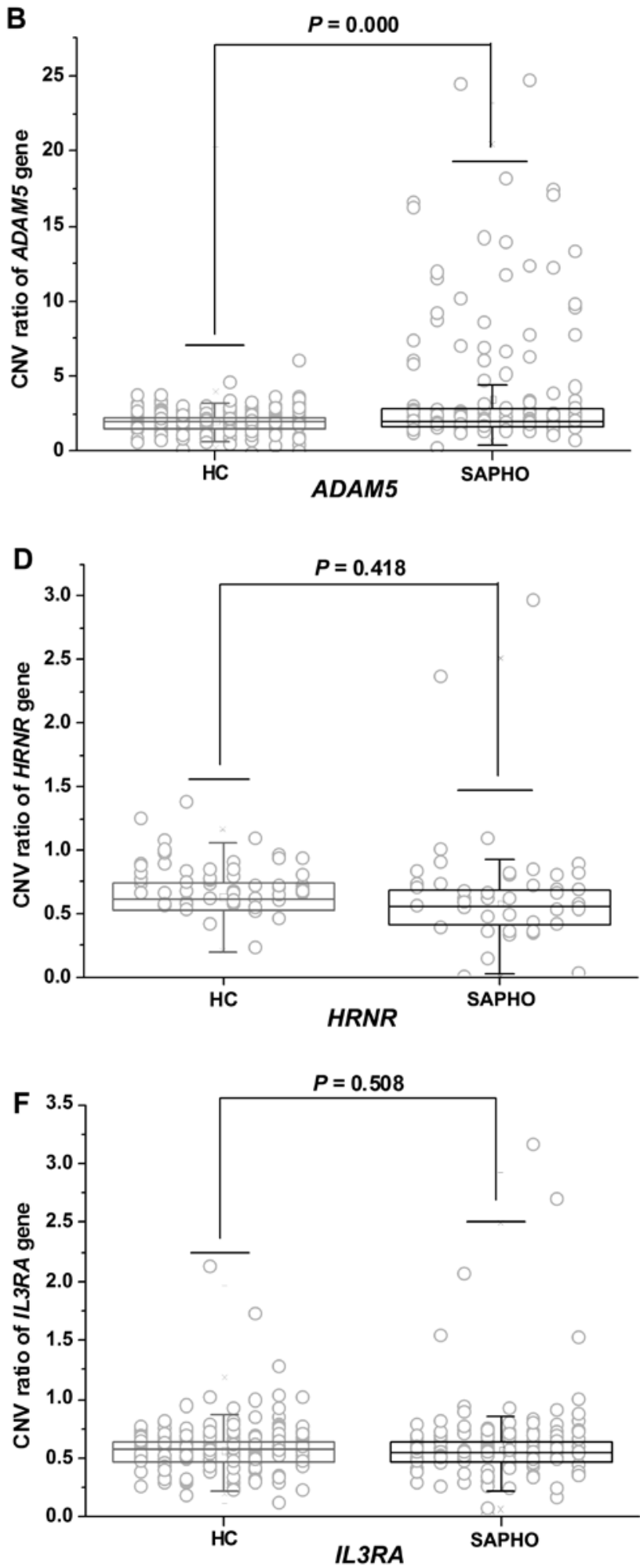

Figure 1. CNV ratio of candidate genes in SAPHO patients and healthy controls (Part A). HC: healthy controls; CNV: copy number variations; SAPHO (synovitis, acne, pustulosis, hyperostosis, osteitis) syndrome.

2. Kerrison C, Davidson JE, Cleary AG, Beresford MW. Pamidronate in the treatment of childhood SAPHO syndrome. Rheumatology 2004;43:1246-51.

3. Matzaroglou C, Velissaris D, Karageorgos A, Marangos M,
Panagiotopoulos E, Karanikolas M. SAPHO syndrome diagnosis and treatment: Report of five cases and review of the literature. Open Orthop J 2009;3:100-6.

4. Hayem G. SAPHO syndrome. Rev Prat 2004;54:1635-6.

\section{Personal non-commercial use only. The Journal of Rheumatology Copyright @ 2020 . All rights reserved.}



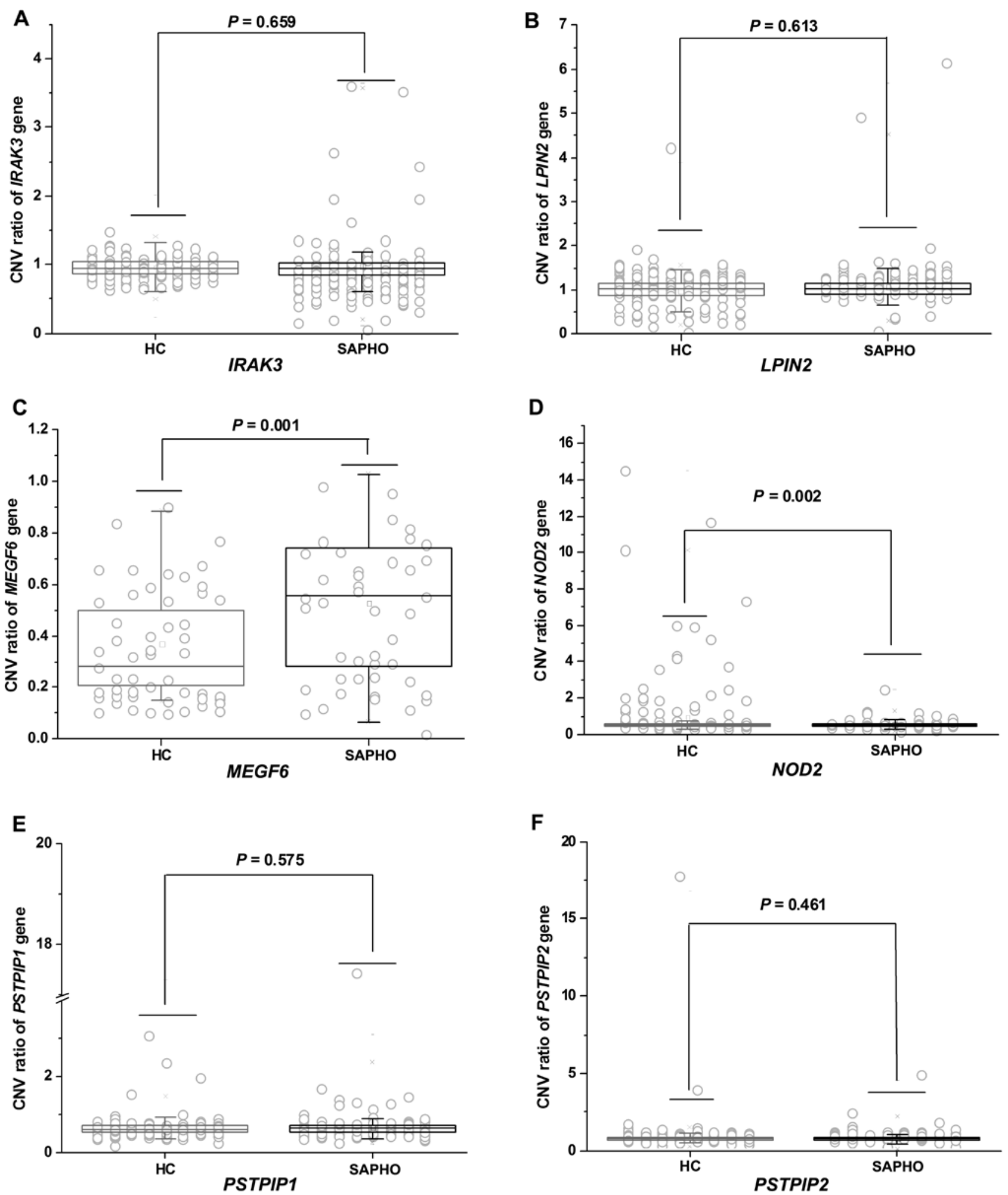

Figure 2. CNV ratio of candidate genes in SAPHO patients and healthy controls (Part B). HC: healthy controls; CNV: copy number variations; SAPHO (synovitis, acne, pustulosis, hyperostosis, osteitis) syndrome.

5. Ferguson PJ, Bing X, Vasef MA, Ochoa LA, Mahgoub A, Waldschmidt TJ, et al. A missense mutation in pstpip2 is associated with the murine autoinflammatory disorder chronic multifocal osteomyelitis. Bone 2006;38:41-7.

6. Liao HJ, Chyuan IT, Wu CS, Lin SW, Chen KH, Tsai HF, et al. Increased neutrophil infiltration, IL-1 production and a 
SAPHO syndrome-like phenotype in PSTPIP2-deficient mice. Rheumatology 2015;54:1317-26.

7. Hurtado-Nedelec M, Chollet-Martin S, Chapeton D, Hugot JP, Hayem G, Gerard B. Genetic susceptibility factors in a cohort of 38 patients with SAPHO syndrome: a study of PSTPIP2, NOD2, and LPIN2 genes. J Rheumatol 2010;37:401-9.

8. Zarrei M, MacDonald JR, Merico D, Scherer SW. A copy number variation map of the human genome. Nat Rev Genet 2015; 16:172-83.

9. Sebat J, Lakshmi B, Troge J, Alexander J, Young J, Lundin P. Large-scale copy number polymorphism in the human genome. Science 2004;305:525-8.

10. Sharma M, Ferguson PJ. Autoinflammatory bone disorders: update on immunologic abnormalities and clues about possible triggers. Curr Opin Rheumatol 2013;25:658-64.

11. Kahn MF, Hayem F, Hayem G, Grossin M. Is diffuse sclerosing osteomyelitis of the mandible part of the synovitis, acne, pustulosis, hyperostosis, osteitis (SAPHO) syndrome? Analysis of seven cases. Oral Surg Oral Med Oral Pathol 1994;78:594-8.

12. Cassel SL, Janczy JR, Bing X, Wilson SP, Olivier AK, Otero JE, et al. Inflammasome-independent IL- $1 \beta$ mediates autoinflammatory disease in Pstpip2-deficient mice. Proc Natl Acad Sci USA 2014;111:1072-7.

13. Colina M, Pippucci T, Moro MA, Marconi C, Magini P, Ciancio G, et al. Synovitis, acne, pustulosis, hyperostosis, osteitis (SAPHO) syndrome: Is PTPN22 involved? Clin Exp Rheumatol 2012;30:451.

14. Ferguson PJ, Laxer RM. New discoveries in CRMO: IL-1beta, the neutrophil, and the microbiome implicated in disease pathogenesis in Pstpip2-deficient mice. Semin Immunopathol 2015;37:407-12.

15. Lacey DL, Timms E, Tan HL, Kelley MJ, Dunstan CR, Burgess T, et al. Osteoprotegerin ligand is a cytokine that regulates osteoclast differentiation and activation. Cell 1998;93:165-76.

16. Helena Mangs A, Morris BJ. The human pseudoautosomal region (PAR): origin, function and future. Curr Genomics 2007;8:129-36.

17. Tanaka S, Takahashi N, Udagawa N, Tamura T, Akatsu T, Stanley $\mathrm{ER}$, et al. Macrophage colony-stimulating factor is indispensable for both proliferation and differentiation of osteoclast progenitors. J Clin Invest 1993;91:257-63.

18. Guo X, Higgs BW, Bay-Jensen AC, Wu Y, Karsdal MA, Kuziora $\mathrm{M}$, et al. Blockade of GM-CSF pathway induced sustained suppression of myeloid and $\mathrm{T}$ cell activities in rheumatoid arthritis. Rheumatology 2018;57:175-84

19. Avci AB, Feist E, Burmester GR. Targeting GM-CSF in rheumatoid arthritis. Clin Exp Rheumatol 2016;34:39-44.
20. Reynolds G, Gibbon JR, Pratt AG, Wood MJ, Coady D, Raftery $\mathrm{G}$, et al. Synovial CD4+ T-cell-derived GM-CSF supports the differentiation of an inflammatory dendritic cell population in rheumatoid arthritis. Ann Rheum Dis 2016;75:899-907.

21. Klimiuk PA, Yang H, Goronzy JJ, Weyand CM. Production of cytokines and metalloproteinases in rheumatoid synovitis is T cell dependent. Clin Immunol 1999;90:65-78.

22. Cook AD, Pobjoy J, Steidl S, Durr M, Braine EL, Turner AL, et al. Granulocyte-macrophage colony-stimulating factor is a key mediator in experimental osteoarthritis pain and disease development. Arthritis Res Ther 2012;14:R199.

23. Papatriantafyllou M. Cytokines: GM-CSF in focus. Nat Rev Immunol 2011;11:370-1.

24. Firinu D, Garcia-Larsen V, Manconi PE, Del Giacco SR. SAPHO syndrome: current developments and approaches to clinical treatment. Curr Rheumatol Rep 2016;18:35.

25. Hampton SL, Youssef H. Successful treatment of resistant SAPHO syndrome with anti-TNF therapy. BMJ Case Rep 2013;2013:bcr2012007161.

26. Ahn S, Jeong D, Oh SJ, Ahn J, Lee SH, Chung DH. GM-CSF and IL-4 produced by NKT cells inversely regulate IL-1beta production by macrophages. Immunol Lett 2017;182:50-6.

27. Berthelot JM, Corvec S, Hayem G. SAPHO, autophagy, IL-1, FoxO1, and Propionibacterium (Cutibacterium) acnes. Joint Bone Spine 2018;85:171-6.

28. Kistowska M, Gehrke S, Jankovic D, Kerl K, Fettelschoss A, Feldmeyer L, et al. IL-1beta drives inflammatory responses to propionibacterium acnes in vitro and in vivo. J Invest Dermatol 2014; 134:677-85.

29. DeGruttola AK, Low D, Mizoguchi A, Mizoguchi E. Current understanding of dysbiosis in disease in human and animal models. Inflamm Bowel Dis 2016;22:1137-50.

30. Yao Q, Li E, Shen B. Autoinflammatory disease with focus on NOD2-associated disease in the era of genomic medicine. Autoimmunity 2019;52:48-56.

31. Wong CK, Chu IM, Hon KL, Tsang MS, Lam CW. Aberrant expression of bacterial pattern recognition receptor NOD2 of basophils and microbicidal peptides in atopic dermatitis. Molecules 2016;21:471.

32. Hruz P, Zinkernagel AS, Jenikova G, Botwin GJ, Hugot JP, Karin M, et al. NOD2 contributes to cutaneous defense against Staphylococcus aureus through alpha-toxin-dependent innate immune activation. Proc Natl Acad Sci USA 2009;106:12873-8. 